Fertility. Of the 42 patients with idiopathic precocious puberty, 8 were married and one was divorced. One of these patients was infertile after 9 years of marriage and 8 women had given birth to 14 healthy children. In addition three unmarried patients had become pregnant, two having therapeutic abortions and one giving birth to a healthy child.

Adult height. Thirty three patients gave details of their heights, which varied between $142 \mathrm{~cm}$ and 175 $\mathrm{cm}$. Seven women were $150 \mathrm{~cm}$ or less in height; in five of these 7 , puberty began before the age of 5 years.

\section{Other types of precocious puberty.}

In the three patients with the McCune-Albright syndrome no pregnancies were reported, although two were married and one had already been investigated for infertility; the third patient reported irregular menstruation. None of the patients with a lesion of the central nervous system had married or attempted conception. In all but one patient the family reported a regular menstrual pattern. The patient who had a granulosa cell tumour had regular menstruation and had had three normal pregnancies.

\section{Discussion}

There are many reports of pregnancy in girls with precocious puberty-Reuben and Manning collected 16 reports of pregnancy and delivery in girls who presented with precocious puberty aged 6 to 10 years. ${ }^{2}$ There is very little information, however, on the outcome for girls with precocious puberty in adult life. The above findings indicate quite clearly that the long term outlook for menstruation and fertility is essentially normal in girls presenting in early childhood with 'constitutional' precocious puberty. All but two patients reported regular menstruation and only one of the 9 women who had attempted conception reported difficulties; this compares well with the infertility rate in the general population.

It is difficult to comment on the other patients with precocious puberty because of the small numbers. Two of the patients with the McCune-Albright syndrome had married; neither had conceived and one had been investigated for infertility. The patient with precocious puberty caused by a granulosa cell tumour had had three normal pregnancies. None of the patients with an intracranial lesion had married and it is not possible to comment on fertility in this group; however, all but one had normal menstruation indicating a normal pituitary axis.

It has long been recognised that precocious puberty may be associated with short stature in adult life, and 7 of 33 of our patients reported that their height was $150 \mathrm{~cm}$ or less; in five of these 7 patients puberty began before the age of 5 years. We have not attempted to verify these measurements, but the results are generally similar to those given by Sigurjonsdottir and Hayles ${ }^{3}$ : out of 34 subjects who had completed their growth, 12 were $150 \mathrm{~cm}$ or less in height and 8 of those 12 had started their pubertal development before the age of 5 years.

\section{References}

1 Murram D, Dewhurst J, Grant DB. Premature menarche; a follow-up study. Arch Dis Child 1983;58:142-3.

2 Reuben MS, Manning GR. Precocious puberty. Archives of Pediatrics 1923;40:27-44.

3 Sigurjonsdottir TJ, Hayles AB. Precocious puberty: a report of 96 cases. Am J Dis Child 1968;115:309-21.

Correspondence to Dr D B Grant, The Hospital for Sick Children, Great Ormond Street, London WC1N 3JH.

Received 6 September 1983

\title{
Short stature caused by obstructive apnoea during sleep
}

\author{
T W P BATE, D A PRICE, C A HOLME, AND R B McGUCKEN
}

Royal Manchester Children's Hospital, Manchester

SUMMARY A 5 year old girl presented to a growth clinic with short stature. Obstructive sleep apnoea was diagnosed. After tonsillectomy her symptoms were alleviated and her rate of growth increased from $4.0 \mathrm{~cm} /$ year to $13.6 \mathrm{~cm} /$ year.
Chronic obstruction of the upper airways may disturb normal sleep physiology in children and adults, leading to apnoea, hypercapnia, and hypoxia. ${ }^{1-3}$ Serious clinical sequelae including learning difficulties, ${ }^{2}$ neurological deficits, cor pumonale, and failure to thrive ${ }^{3}$ have been described in children. Although poor weight gain has been 
reported in some children, ${ }^{3}$ evidence of the effect on height and weight velocity has not been published.

\section{Case report}

A girl aged 4 years 4 months was referred to a regional growth clinic for assessment and investigation of short stature and poor growth noticed since the age of $2^{1 / 2}$ years. The mean parental height centile was the 75th and her birthweight was $4.5 \mathrm{~kg}$. She showed symptoms of chronic obstruction of the upper airways, breathing persistently through her mouth with snoring and restlessness at night. Examination showed nasal obstruction, large tonsils, weight and height below the third centile, and systolic blood pressure $90 \mathrm{~mm} \mathrm{Hg}$.

Six months after an otolaryngological assessment and unsuccessful treatment with nasal decongestants, adenoidectomy failed to improve her respiratory symptoms. Her growth velocity was poor and she was admitted for investigation. Further investigations showed that her sleep was so disturbed that she was difficult to rouse in the morning, somnolent during the day, and performing badly at school. While in hospital she often had episodes of apnoea (10-15 seconds duration) when asleep. A chest radiograph showed cardiomegaly and an electrocardiogram (Fig. 1) showed tall peaked $P$ waves and
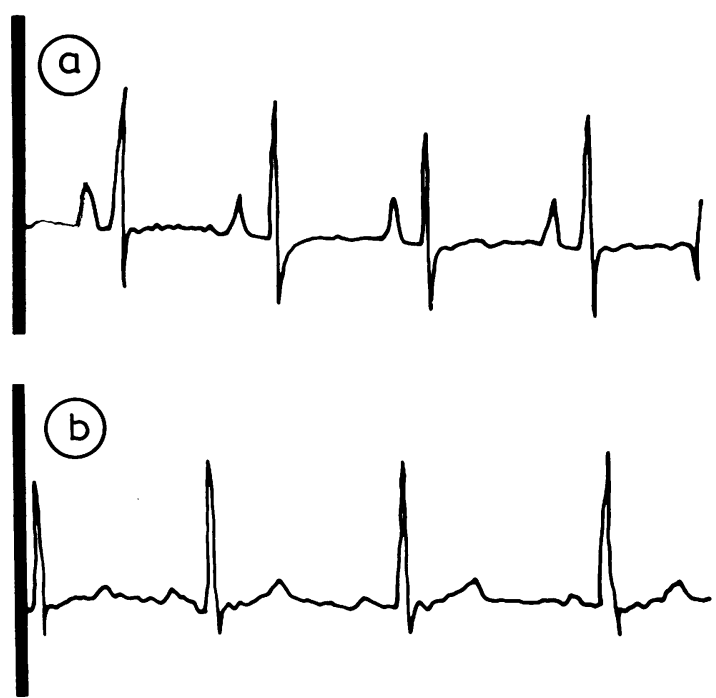

Fig. 1 Presence of peaked $P$ waves in electrocardiogram, standard lead II, in a child with obstructive sleep apnoea, and disappearance after relief of obstruction by tonsillectomy. (a) Electrocardiogram recorded before tonsillectomy. (b) Electrocardiogram recorded 6 months after tonsillectomy.

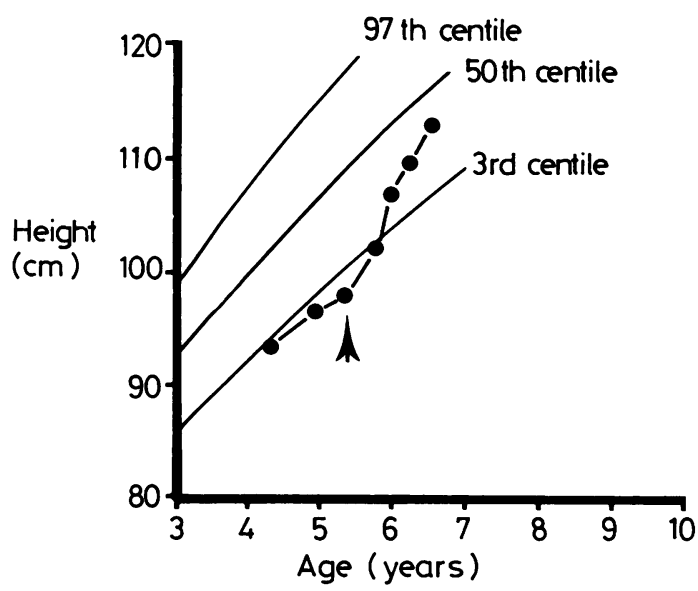

Fig. 2 Effect of tonsillectomy on height in a child with obstructive sleep apnoea. The arrow indicates tonsillectomy.

evidence of right ventricular enlargement. During sleep an arterial blood sample showed $\mathrm{pH} 7 \cdot 27$, oxygen tension $9.8 \mathrm{kpa}(79 \mathrm{~mm} \mathrm{Hg})$, and carbon dioxide tension $7 \cdot 4 \mathrm{kpa}(59 \mathrm{~mm} \mathrm{Hg})$. Serum growth hormone concentrations during sleep rose to 74 $\mathrm{mU} / \mathrm{l}$

Tonsillectomy was performed, and the child's sleep pattern returned to normal. Parents, friends, and teachers commented on the improvement in her health. She became alert and attentive during the day and her school work improved. Before tonsillectomy her height and weight velocities were $4 \cdot 0$ $\mathrm{cm} /$ year and $1.9 \mathrm{~kg} /$ year (Fig. 2); these increased to $13.5 \mathrm{~cm} /$ year and $5.9 \mathrm{~kg} /$ year respectively, measured over a full year. Electrocardiograms and chest radiographs 6 months after tonsillectomy showed no abnormalities (Fig. 1).

\section{Discussion}

Obstructive apnoea during sleep in young children may lead to failure to thrive. ${ }^{3}$ So far, however, studies have reported data on weight gain alone, although almost certainly linear growth is also affected. We are not certain of the pathogenesis of poor linear growth in our patient. Disturbed sleep might have led to impaired growth hormone secretion, but this clearly was not the case. If growth is impaired by the continued stress of chronic ill health we are still no closer to understanding the mechanism. Tissue acidosis may impair end organ response to growth factors, and conditions leading to acidaemia adversely affect growth in children. ${ }^{4} \mathrm{We}$ believe nocturnal acidaemia due to carbon dioxide 
retention may have been an important factor in retarding this child's growth.

Obstructive apnoea during sleep is not often diagnosed in the United Kingdom, ${ }^{5}$ but there are no good reasons to think that it is a less common condition than in North America. ${ }^{6}$ We believe that it would be diagnosed more often if parents were questioned, and listened to, about sleep and the child was examined while sleeping.

We are grateful to Mrs K Cordwell and the Salford Department of Medical Illustration.

References

${ }^{1}$ Gastaut H, Tassinari A, Duron B. Polygraphic study of the episodic diurnal and nocturnal (hypoxic and respiratory) manifestations of the Pickwick syndrome. Brain Res 1966;2:167-86.

2 Guilleminault C, Eldridge FL, Simmonds FB, Dement WC. Sleep apnea in eight children. Pediatrics 1976;58:23-30.

${ }^{3}$ Brouillette RT, Fernbach SK, Hunt CE. Obstructive sleep apnea in infants and children. $J$ Pediatr 1982;100:31-40.

${ }^{4}$ Daughaday WH. Hormonal regulation of growth by somatomedin and other tissue growth factors. Clin Endocrinol Metab 1977;i:119.

5 Apps MCP, Moore Gillon JC, Stradling JR. Underdiagnosis of obstructive sleep apnoea in Britain (letter). Lancet 1983;i:1054.

${ }^{6}$ McNicholas WT, Tarlo SM, Phillipson EA. Is sleep apnoea more common in North America? (letter). Lancet 1982;i:458.

Correspondence to Dr D A Price, Senior Lecturer in Child Health, Department of Child Health, Royal Manchester Children's Hospital, Pendlebury, Manchester M24 1HA.

Received 28 September 1983

\title{
Transverse myelitis associated with Mycoplasma pneumoniae infection
}

\author{
P I MACFARLANE AND V MILLER
}

Booth Hall Children's Hospital, Manchester

SUMMARY A case of acute transverse myelitis associated with respiratory infection by Mycoplasma pneumoniae is described. Circulating antibodies to myelin were detected suggesting that mycoplasma related neurological damage is mediated by producing an immunological myelopathy.

Neurological complications of infection with $\mathrm{Myco}$ plasma pneumoniae have affected the meninges, cerebellum, cerebrum, spinal cord, and nerve roots. ${ }^{1}$ The pathogenesis of the neurological disorder is uncertain. Evidence suggests an immunological mechanism acting against myelin and nerve cells. ${ }^{2}$

We report on a child with acute transverse myelitis and aseptic meningitis. There was evidence of production of $M$ pneumoniae antibody in the blood but no evidence of local antibody synthesis in cerebrospinal fluid (CSF). Antibodies to myelin were shown in blood.

\section{Case report}

A 14 year old girl presented 10 days after onset of rhinorrhoea, cough, and intermittent pyrexia. Two days before admission she had developed ascending paraesthesia and numbness in both legs. This progressed to total paraplegia. Abnormal clinical findings were confined to the nervous system. She showed mild meningism but was fully conscious. The functions of the cranial nerves, cerebellum, and arms were normal. A complete flaccid paraplegia with areflexia and bilateral extensor plantar responses was noted in her legs as was loss of sensation up to her mid abdomen (level T9-10). Her bladder was palpable. Position and vibration sense was absent in both legs. A chest radiograph showed patchy consolidation in the left lower lobe of the lungs. An extrinsic compressive cord lesion was excluded by myelography.

CSF collected during the procedure contained 50 leucocytes $/ \mu$ l $(30 \%$ polymorphs, $70 \%$ monocytes). A low CSF glucose concentration $(2.4 \mathrm{mmol} / \mathrm{l}(43$ $\mathrm{mg} / 100 \mathrm{ml})$, blood glucose $6 \cdot 3 \mathrm{mmol} / 1(114 \mathrm{mg} / 100$ $\mathrm{ml})$ and raised protein concentration $(1.3 \mathrm{~g} / \mathrm{l})$ were noted. CSF was sterile. An initial blood film showed considerable autoagglutination of red cells and total white cell count of $12.5 \times 10^{9} / 1(82 \%$ neutrophils, $15 \%$ lymphocytes, $3 \%$ monocytes). Mycoplasma related acute transverse myelitis was provisionally diagnosed.

Treatment was started with erythromycin and prednisolone. Bladder catheterisation and rectal washouts were required. Over the first 48 hours the 